\title{
Comparison of HMOX1 expression and enzyme activity in blue-shelled chickens and brown-shelled chickens
}

\author{
Zhepeng Wang ${ }^{1}$, Ruifang Liu ${ }^{1}$ and Anru Wang ${ }^{2}$ \\ ${ }^{1}$ College of Animal Science and Technology, Northwest A\&F University, Yangling, \\ Shaanxi Province, P.R. China. \\ ${ }^{2}$ State Key Laboratory of Direct-Fed Microbial Engineering, Beijing, P.R. China.
}

\begin{abstract}
Blue egg coloring is attributed to biliverdin derived from the oxidative degradation of heme through catalysis by heme oxygenase $(\mathrm{HO})$. The pigment is secreted into the eggshell by the shell gland. There is uncertainty as to whether the pigment is synthesized in the shell gland or in other tissues. To investigate the site of pigment biosynthesis, the expression of heme oxygenase (decycling) 1 (HMOX1), a gene encoding $\mathrm{HO}$, and $\mathrm{HO}$ activity in liver and spleen were compared between blue-shelled chickens $(n=12)$ and brown-shelled chickens $(n=12)$. There were no significant differences in HMOX1 expression and $\mathrm{HO}$ activity in these tissues between the two groups. Since the liver and spleen, two important sites outside the shell gland where heme is degraded into biliverdin, $\mathrm{CO}$ and $\mathrm{Fe}^{2+}$, did not differ in $\mathrm{HO}$ expression and activity we conclude that the pigment is most likely synthesized in the shell gland.
\end{abstract}

Keywords: biliverdin, blue egg, chicken, $H M O X 1$.

Received: September 27, 2012; Accepted: March 13, 2013.

\section{Introduction}

The blue color of some eggs is attributed to biliverdin (Kennedy and Vevers, 1973), a green tetrapryrrolic bile pigment that is secreted into the eggshell by the shell gland (Lang and Wells, 1987). Although the identity of blue egg pigment is well-known, the site of eggshell biliverdin synthesis has been disputed for many years. Some researchers believe that eggshell pigments are synthesized in the shell gland and cite as evidence for this the fact that (1) the shell glands of blue-shelled chickens contain higher levels of biliverdin than those of brown-shelled chickens (Zhao et al., 2006; Wang et al., 2009), (2) the activities of enzymes involved in porphyrin synthesis are higher in the shell gland of Rhode Island Red chickens that lay brown eggs than in a mutant strain laying white eggs that contain a negligible amount of porphyrin (Schwartz et al., 1980) and (3) porphyrin pigments are present in epithelial cells of the shell gland during formation of the eggshell and fluctuations in their levels accompany eggshell formation (Tamura et al., 1965). However, others have considered it improbable that the shell gland synthesizes such large amounts of porphyrin; in this case, blood is the most likely source of the pigment because of its ability to synthesize porphyrin that then reaches the shell gland via the circulation (Baird et al., 1975).

Send correspondence to Anru Wang. Dongsheng Technological Zone, Northern Territory, Building B-3, 66 Xixiaokou Road, 100192 Haidian District, Beijing, P.R. China. E-mail: anruwang @ sohu.com.
Bile biliverdin is derived from the oxidative degradation of heme (Maines, 1997). In mammals, biliverdin is rapidly reduced to bilirubin by biliverdin reductase, secreted into the bile and ultimately excreted via the intestines. However, in birds, the low level of biliverdin reductase activity means that biliverdin is the main metabolite in bile pigment (Himes and Cornelius, 1975). In enterohepatic circulation, large amounts of bilirubin are absorbed into blood from the ileum and transported to the liver via the portal vein; little escapes the liver to reach the systemic circulation (Small et al., 1972). However, the production of bilirubin that exceeds the livers capacity results in hemolytic jaundice which can reach other tissues via the blood to cause jaundice (Gilmore and Garvey, 2007). Similarly, excess biliverdin produced in blue-shelled chickens can reach the shell gland, leading to blue-colored eggs.

$\mathrm{HO}$ is a limiting-rate enzyme that catalyzes the degradation of heme to biliverdin, $\mathrm{CO}$ and $\mathrm{Fe}^{2+}$ (Maines, 1997). In view of the role of HO in the formation of biliverdin, heme oxygenase (decycling) 1 (HMOX1), the gene encoding $\mathrm{HO}$, is a key candidate gene for studying the molecular mechanism of blue egg formation. Previous studies of $H M O X 1$ expression in shell gland suggested that the blue egg coloring was associated with high gene expression in the shell gland of blue-shelled chickens (Wang et al., 2010, 2011). However, the pattern of $H M O X 1$ expression in other tissues remains unclear. Hepatic and splenic reticuloendothelial cells are two important sites where heme is de- 
graded to biliverdin (Hudson and Smith, 1975). Hence, analysis of $H M O X I$ expression and $\mathrm{HO}$ activity in these tissues will be helpful in understanding the origin of eggshell biliverdin.

\section{Material and Methods}

\section{Animals}

Twelve Dongxiang blue-shelled chickens and 12 Dongxiang brown-shelled chickens were slaughtered 3-5 h prior to laying. Livers and spleens were collected and immediately stored in liquid nitrogen for further analysis. All chickens were provided by a local breed protection farm in DongXiang town, JiangXi province, China.

\section{RNA isolation, reverse transcription and real-time PCR}

Total RNA was extracted with TRIzol reagent (TianGen Corp., Beijing, China). Two micrograms of total RNA was reverse transcribed into cDNA in a volume of $25 \mu \mathrm{L}$ consisting of $0.5 \mu \mathrm{g}$ of oligo(dT) 15 primer, $5 \mu \mathrm{L}$ of 5xfirst-strand buffer, $5 \mu \mathrm{L}$ of $10 \mathrm{mM}$ dNTP, $25 \mathrm{U}$ of ribonuclease inhibitor, $200 \mathrm{U}$ of M-MLV reverse transcriptase (Promega, Fitchburg, WI, USA) and RNase-free water to final volume of $25 \mu \mathrm{L}$.

Real-time PCR was done in an ABI PRISM 7900 instrument (Applied Biosystems Corp., Foster, CA, USA). cDNA $(1 \mu \mathrm{L})$ was amplified in $20 \mu \mathrm{L}$ according to the RealMasterMix (SYBR Green I) protocol (Tiangen Corp.). Samples were assayed in triplicate and the data were analyzed by the method (Livak and Schmittgen, 2001). $G A P D H$ was used as an endogenous reference to normalize the amount of cDNA used in the PCR and brown-shelled chickens were used as the calibrator. The amount of $H M O X 1$ transcripts, normalized to $G A P D H$ and relative to the calibrator, was given by. The HMOXI forward and reverse primers were 5'-ATCGCATGAAAACAGTCCAG-3 ' and 5'-CAAATAAGCCCACGGCGAC-3', respectively, and the $G A P D H$ forward and reverse primers were 5'-ATACACAGAGGACCAGGTTG-3' and 5'-AAACTCATTGTCATACCAGG-3', respectively.

\section{Western blotting}

Total protein was extracted from individual frozen liver and spleen samples using $500 \mu \mathrm{L}$ of lysis buffer consisting of $7 \mathrm{M}$ urea, $2 \mathrm{M}$ thiourea, $60 \mathrm{mM}$ dithiothreitol (DTT) and 4\% 3-[(3-cholamidopropyl)-dimethylammonio]-propane-sulfonate (CHAPS). Protein from three individuals was pooled into a sample (with four pools or groups per eggshell color). Protein concentration was determined using a Bradford dye-binding protein assay kit (Jiancheng Bioengineering Institute, NanJing, China). Twenty micrograms of total protein were separated by SDS-PAGE on $10 \%$ gels followed by a transfer to a nitrocellulose mem- brane $(0.45 \mu \mathrm{m})$ at $100 \mathrm{~V}$ for $1 \mathrm{~h} 20 \mathrm{~min}$. The membrane was subsequently incubated in blocking buffer $(3 \%$ BSA and $0.1 \%$ Tween 20) for $1 \mathrm{~h}$ at $37^{\circ} \mathrm{C}$ and then for $1 \mathrm{~h}$ at $37^{\circ} \mathrm{C}$ in blocking buffer containing rabbit anti-HO-1 antibody (dilution 1:200, Biosynthesis Biotechnology Co., Beijing, China) and $\beta$-actin antibody (dilution 1:2000, Biosynthesis Biotechnology Co.). After three washes in TBST (10 mM Tris-HCl, $\mathrm{pH} 8.0 ; 150 \mathrm{mM} \mathrm{NaCl} ; 0.1 \%$ Tween 20) for $10 \mathrm{~min}$ each, the membrane was exposed to horseradish peroxidase-conjugated secondary antibodies at $37{ }^{\circ} \mathrm{C}$ for $1 \mathrm{~h}$. After three washes in TBST, the bands were visualized by exposing the membrane to diaminobenzidine (DAB) for 3-5 min.

\section{$\mathrm{HO}$ activity assay}

$\mathrm{HO}$ activities in liver and spleen were evaluated spectrophotometrically by measuring bilirubin formation (McCoubrey, 1999). Briefly, $15 \mu \mathrm{L}$ of fresh microsomes (protein concentration: $8 \mathrm{mg} / \mathrm{ml}$ ) was added to a reaction mixture containing $6 \mu \mathrm{L}$ of $2.75 \mathrm{mM}$ NADPH (substituted by $\mathrm{HO}$ assay buffer in the reference tube), $10 \mu \mathrm{L}$ of procine kidney cytosolic fraction as a source of biliverdin reductase ( $0.9 \mathrm{U}$ total), $26 \mu \mathrm{L}$ of $\mathrm{HO}$ assay buffer and $9 \mu \mathrm{L}$ of $1 \mathrm{mM}$ hemin (substrate). The samples and reference tubes were incubated for $20 \mathrm{~min}$ at $37^{\circ} \mathrm{C}$ in the dark with constant shaking. The reaction was stopped by placing the tubes in an ice bath. The solution in the reference tube was used as blank in the spectrophotometer (NanoDrop 1000, Thermo Fisher Scientific Inc.) readings done between $410 \mathrm{~nm}$ and $610 \mathrm{~nm}$. The difference in absorption between $470 \mathrm{~nm}$ and $530 \mathrm{~nm}$ was determined and the concentration of bilirubin was calculated using an extinction coefficient of $40 \mathrm{mM}^{-1}$ $\mathrm{cm}^{-1}$. One unit of $\mathrm{HO}$ activity was defined as the production of $1 \mathrm{nmol}$ of bilirubin/h.

\section{Statistical analysis}

The results were expressed as the mean + SEM. Statistical comparisons were done using Students $t$-test with a value of $p<0.05$ indicating significance. All data analyses were done using the statistical software package SAS v.8.2.

\section{Results}

The liver and spleen are two tissues in which heme is oxidatively degraded to biliverdin, $\mathrm{CO}$ and $\mathrm{Fe}^{2+}$. As shown here, $H M O X 1$ expression and $\mathrm{HO}$ activity were detected in both of these tissues in blue-shelled and brown-shelled chickens. However, there was no significant difference in the HMOX1 mRNA levels in liver or spleen in these two groups of chickens (Figure 1). In agreement with this, there was also no significant difference in the hepatic and splenic protein expression of HO- 1 between the two groups, as assessed by western blotting (Figure 2). This finding was fur- 

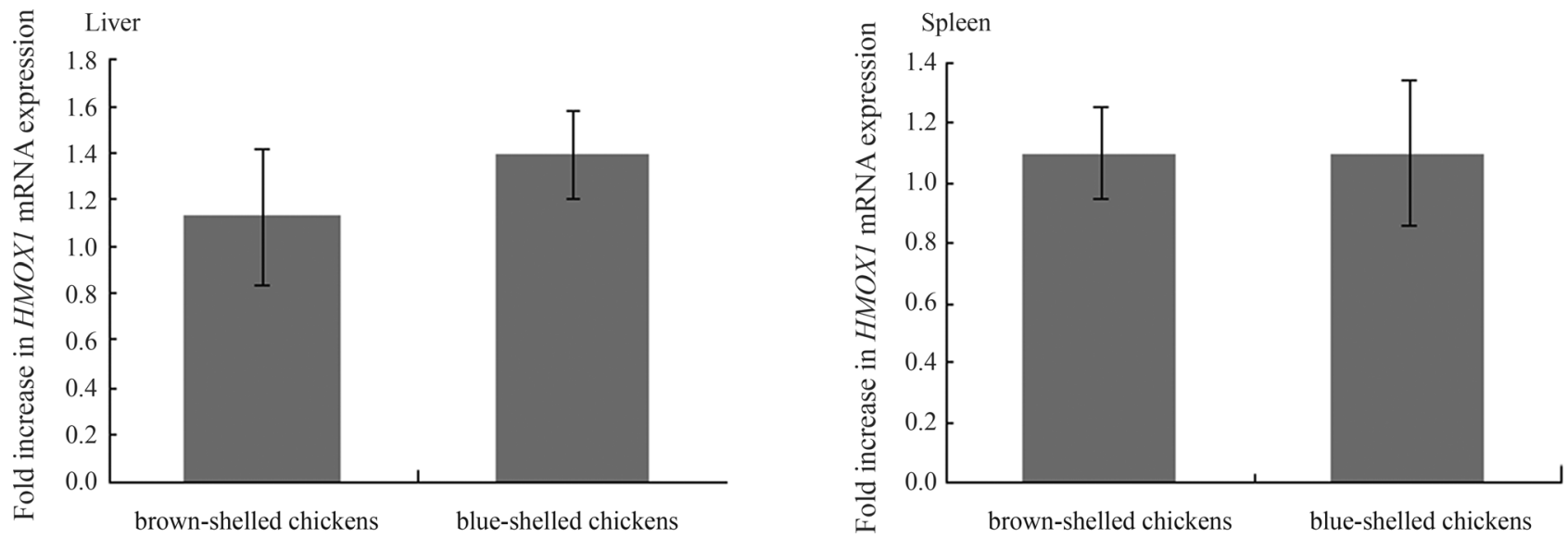

Figure 1 - Quantitative real-time RT-PCR analysis of HMOX1 expression in brown-shelled chickens and blue-shelled chickens. The bars represent the mean + SEM fold increase in HMOXI transcript expression relative to the brown-shelled group given by $2^{-\Delta \triangle C T}$ ( $\mathrm{n}=12$ per group). Blue-shelled chickens expressed 1.39 fold more transcripts in liver than brown-shelled chickens, but the difference was not significant. There was also no significant difference in the level of spleen $H M O X 1$ transcripts in the two groups.

Liver

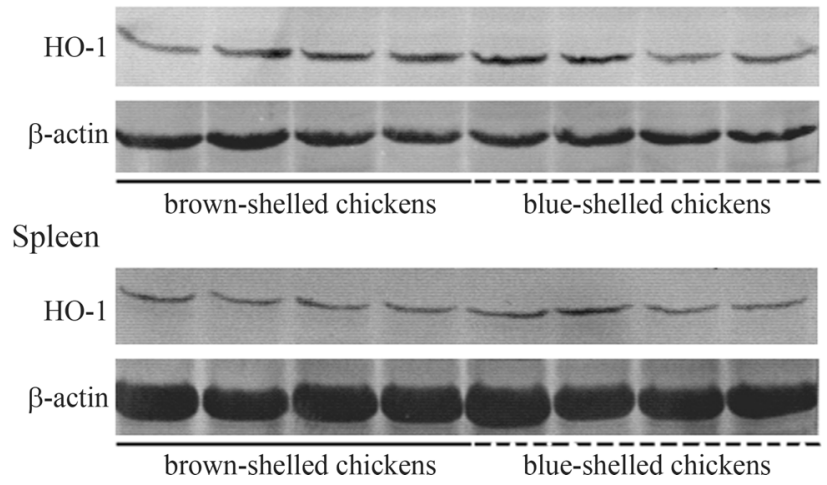

Figure 2 - HO-1 protein expression. Protein extracts from three chickens in each group were pooled and each pool was assayed four times for HO-1 protein by western blotting. The four replicates are shown in the blots. The two groups of chickens expressed similar amounts of HO-1 protein in liver and spleen.

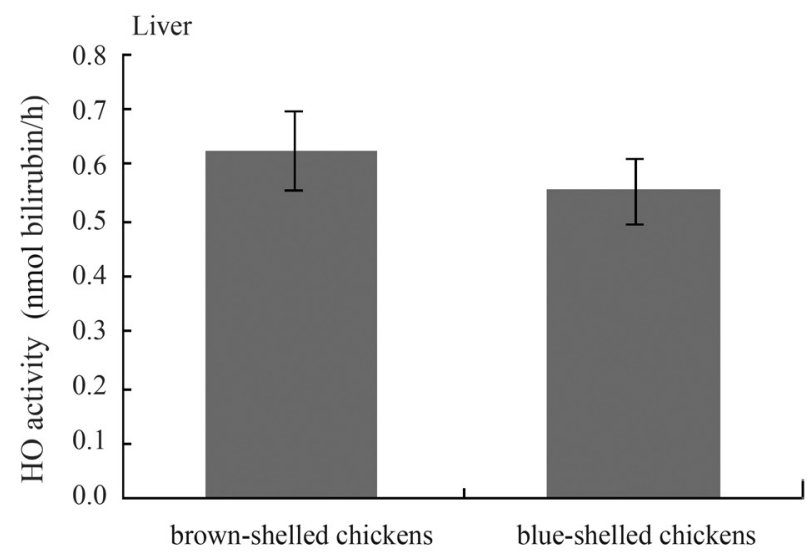

ther supported by a lack of difference in HO-1 activity between the two groups (Figure 3).

\section{Discussion}

Blue is a common eggshell color in birds, not only in domestic fowls such as chicken (Punnett, 1933), duck (Wang et al., 1997) and quail (Ito et al., 1993), but also in wild birds such as eastern bluebird (Siefferman et al., 2006), blue-footed booby (Morales et al., 2010), and pied flycatcher (Moreno et al., 2005). The blue color is considered to be a signal to males of a female's state of health such that males are more likely to remain around nests and help rear the young (Moreno and Osorno, 2003). The blue color derives from biliverdin, a breakdown product of heme. However, the site of synthesis of this biliverdin remains unresolved.

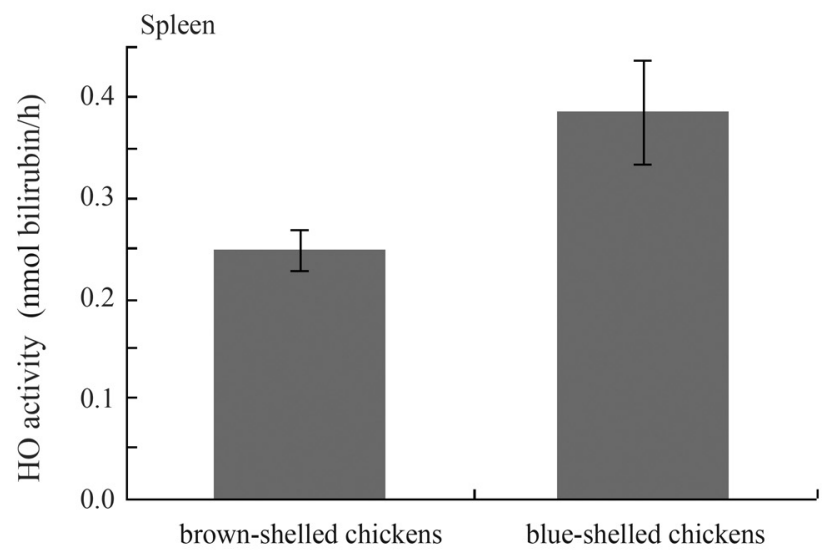

Figure 3 - Hepatic and splenic HO activity. Enzymatic activity was assayed by measuring bilirubin formation. There were no significant differences in the hepatic and splenic HO activities between brown-shelled chickens and blue-shelled chickens. The columns are the mean + SEM of 12 chickens per group. 
Previous studies have shown that the shell gland and eggshell of blue-shelled chickens contain higher levels of biliverdin than those of brown-shelled chickens (Zhao et al., 2006; Wang et al., 2009). These findings suggest that biliverdin is synthesized in the shell gland. Since biliverdin in bile is synthesized mainly in liver and spleen it is possible that biliverdin in eggshell may be derived from these tissues, being transported to the shell gland via the blood. To address this question, we examined the expression levels of $H M O X 1$ in liver and spleen. If $H M O X 1$ were highly expressed in these two tissues of blue-shelled chickens it would suggest a greater efficiency of biliverdin biosynthesis in these tissues, thereby providing additional evidence that eggshell biliverdin is synthesized outside the shell gland. However, our data indicate that there were no significant differences in HO-1 expression or activity in either tissue from the two groups of chickens (Figures 1-3). This finding agrees with that of Zhao et al. (2006) who also observed no significant difference in the bile biliverdin levels in these two groups of chickens. Together, these data indicate that there is insufficient bile biliverdin to escape from the enterohepatic circulation to the shell gland in blueshelled chickens.

In laying hens, the shell gland is a highly vascular organ. When the egg reaches the shell gland, the metabolism of this organ is stimulated, blood flow increases (Kennedy and Vevers, 1973; Baird et al., 1975) and protoporphyrin (the precursor of heme, another eggshell pigment responsible for red-brown eggshell color) is released during erythrocyte disintegration and is transported to the surface of the eggshell by wandering cells (Baird et al., 1975). Based on current knowledge of the process of protoporphyrin deposition it is conceivable that heme resultant from erythrocyte degradation can be converted to biliverdin by HO-1 in the shell gland of blue-shelled chickens since this organ has a high expression of HMOXI (Wang et al., 2010, 2011) and would result in blue-colored eggs.

In conclusion, our data support the hypothesis that eggshell biliverdin is synthesized in the shell gland. Although this study and previous reports (Wang et al., 2010, 2011) have focused on $H M O X 1$, a gene associated with the biosynthesis of biliverdin, future studies should examine the mechanism by which biliverdin is transported.

\section{Acknowledgments}

The authors thank Xu JianSheng and Chen YunLong for providing samples. This work was funded by the Northwest Scientific Startup Foundation for Doctors (Z109021112), the National Nature Science Foundation (31072024) and the Lueyang Chicken Breeding Project of Northwest A\&F University (Z109021127).

\section{References}

Baird T, Solomon SE and Tedstone DR (1975) Localisation and characterisation of eggshell porphyrin in several avian species. Br Poult Sci 16:201-208.

Gilmore I and Garvey CJ (2007) Investigation of jaundice. Medicine 35:42-46.

Himes JA and Cornelius CE (1975) Biliverdin and bilirubin excretion in the turkey. Cornell Vet 65:374-379.

Hudson MF and Smith KM (1975) Bile pigments. Chem Soc Rev 4:363-399.

Ito S, Tsudzuki M, Komori M and Mizutani M (1993) Celadon: An eggshell color mutation in Japanese quail. J Hered 84:145-147.

Kennedy GY and Vevers HG (1973) Eggshell pigments of the Araucano fowl. Comp Biochem Physiol B 44:11-25.

Lang MR and Wells JW (1987) A review of eggshell pigmentation. World's Poult Sci 43:238-245.

Livak KJ and Schmittgen TD (2001) Analysis of relative gene expression data using real-time quantitivative PCR and the $2^{-\Delta \Delta \mathrm{CT}}$ method. Methods 25:402-408.

Maines MD (1997) The heme oxygenase system: A regulator of second messenger gases. Annu Rev Pharmacol Toxicol 37:517-554.

McCoubrey WKJ (1999) Detection of heme oxygenase 1 and 2 proteins and bilirubin formation. In: Costa LG, Hodgson E, Lawrence DA and Reed DJ (eds) Current Protocols in Toxicology. John Wiley \& Sons, New York, pp 9.3.1-9.3.9.

Morales J, Torres R and Velando A (2010) Parental conflict and blue egg coloration in a seabird. Naturwissenschaften 97:173-180.

Moreno J and Osorno JL (2003) Avian egg colour and sexual selection: Does eggshell pigmentation reflect female condition and genetic quality? Ecol Lett 6:803-806.

Moreno J, Morales J, Lobato E, Merino S, Tomás G and Martínez de la Puente J (2005) Evidence for the signaling function of egg color in the pied flycatcher Ficedula hyoleuca. Behav Ecol 16:931-937.

Punnett RC (1933) Genetic study in poultry-IX. The blue egg. Genetics 27:465-470.

Schwartz S, Raux WA, Schacter BA, Stephenson BD and Shoffner RN (1980) Loss of hereditary uterine protoporphyria through chromosomal rearrangement in mutant Rhode Island Red hens. Int J Biochem 12:935-940.

Siefferman L, Navara KJ and Hill GE (2006) Egg coloration is correlated with female condition in eastern bluebirds (Sialia sialis). Behav Ecol Sociobiol 59:651-656.

Small DM, Dowling RH and Redinger RN (1972) The enterohepatic circulation of bile salts. Arch Intern Med 130:552573.

Tamura T, Fujii S, Kunisaki H and Yamane M (1965) Histological observations on the quail oviduct: With reference to pigment (porphyrin) in the uterus. J Fac Fish Anim Husband 6:37-57.

Wang CT, Wan TC, Pan CM and Chen YH (1997) Comparisons of physical-chemical properties and alkalizing process between greenish and whitish eggs of Brown Tsaiya duck. J Chin Agri Chem Soc 35:263-272.

Wang XT, Zhao CJ, Li JY, Xu GY, Lian LS, Wu CX and Deng XM (2009) Comparison of the total amount of eggshell pigments in Dongxiang brown-shelled eggs and Dongxiang blue-shelled eggs. Poult Sci 88:1735-1739. 
Wang XT, Zhao CJ, Li JY, Xu GY, Lian LS, Wu CX and Deng $\mathrm{XM}$ (2010) Heme oxygenase-1 is important to the formation of eggshell biliverdin in chicken. J Appl Anim Res 38:229232.

Wang ZP, Liu RF, Wang AR, Li JY and Deng XM (2011) Expression and activity analysis reveal that heme oxygenase (decycling) 1 is associated with blue egg formation. Poult Sci 90:836-841.
Zhao R, Xu GY, Liu ZZ, Li JY and Yang N (2006) A study on eggshell pigmentation: Biliverdin in blue-shelled chickens. Poult Sci 85:546-549.

Associate Editor: Alexandre Rodrigues Caetano

License information: This is an open-access article distributed under the terms of the Creative Commons Attribution License, which permits unrestricted use, distribution, and reproduction in any medium, provided the original work is properly cited. 